\title{
PENSAR CON LOS PIES: DINÁMICAS ELOCUTIVAS, CORPORALES Y EMOCIONALES EN LA PRÁCTICA DE VIDEOJUEGO
}

Por:

Julián González

Estudiante del Doctorado

de Psicología

Universidad del Valle

Profesor titular

Escuela de Comunicación Social

Universidad del Valle

Cali, Colombia

piolin1966@yahoo.com

\section{Olga Lucía Obando}

Profesora Instituto

de Psicología ${ }^{1}$

Universidad del Valle

Cali, Colombia

olgaoba@univalle.edu.co

\section{Resumen:}

Este estudio examina en detalle la actividad de videojuego de un niño de siete años, con buen rendimiento escolar, competente y hábil en términos de desempeño motor, de expresión emocional y expresión verbal. Sugiere que ciertos movimientos rítmicos del cuerpo, cierto tipo de verbalizaciones y ciertos estados emocionales no son eventos periféricos a los procesos de resolución de los videojuegos, constituyen componentes de primer orden de una cognición situada y corporalizada, mediante la cual se resuelven tareas que exceden una comprensión puramente lógica y mentalista. Este estudio propone un conjunto de procedimientos para capturar y analizar este tipo de eventos, en condiciones casi naturales y no experimentales, atendiendo a las particulares restricciones y regulaciones temporales que modulan la actividad de videojuego. (122 palabras)

\section{Palabras claves:}

cognición situada, juego elocutivo, juego silencioso, actividad de videojuego. 
En un estudio previo publicado en este número de la revista (González \& Obando, 2010), se examinaba la presencia de importante actividad elocutiva en medio del videojugar silencioso y de una rítmica particular y emergente, no inscrita en la estructura lógica del videojuego, derivada de las relaciones entre estados de juego y no juego mientras se videojuega. La conclusión esencial de este estudio exploratorio se resume en los siguientes términos: contrario a lo que se esperaba, durante los pasajes de videojuego en que el videojugador tenía mayores dificultades para avanzar, hubo menos actividad elocutiva, que durante los pasajes de la Situación de Videojuego (SVJ) (González \& Obando, 2008 a y b, 2010) en que el videojugador parecía tener mayor dominio y solvencia. Este hallazgo al examinar una SVJ concreta, desafía la hipótesis planteada en el estudio según la cual el aumento en las exigencias del videojuego (por una menor pericia del videojugador, por la presencia de mayores restricciones de tiempo para resolver la tarea de videojuego o una mayor complejidad del videojuego) se traduciría en un aumento general de la actividad elocutiva.

En esta oportunidad nos proponemos examinar si la menor presencia de actividad elocutiva en los pasajes de mayor dificultad de la práctica de videojuego estudiada, se explicaría porque está menor presencia se compensa con una mayor inestabilidad en las posiciones corporales y en los estados emocionales. Para avanzar en el análisis de la SVJ, haremos uso de Gridware (Lewis, Lamey \& Douglas, 1999; Lamey, Hollenstein, Lewis \& Granic, 2004), para estudiar el comportamiento de los tres aspectos (estados emocionales, reacomodos corporales y estados elocutivos) durante toda la trayectoria o desarrollo de la SVJ.

\section{Cronogramas de videojuego y uso del gridware}

El State Space Grids y el Gridware constituye un tipo de herramienta informática y un software inspirado en algunas de las categorías operativas y conceptuales más seductoras de los Sistemas Dinámicos No Lineales: atractores, ruinas de atractores, auto-organización, transiciones de fase, espacio de estados del sistema, trayectorias. Desarrollado por Marc Lewis y su equipo hacia el año 1999, el software ha ido ganando en refinamientos y posibilidades. Hollenstein (2007) señala que mientras la discusión acerca de qué constituye un Sistema Dinámico No Lineal no termina de zanjarse y definirse, es decir, mientras sigue viva la discusión acerca de si únicamente el sistema de ecuaciones matemáticas que lo representa es un SDNL o si, además de las representaciones matemáticas, un sistema dinámico puede representarse por otras vías, incluyendo las ecuaciones, de alguna manera el desarrollo de Gridware constituye en cierta forma un modo de salirle al paso a la discusión, en tanto permite abordajes dinámicos de procesos empíricos sin tener que pasar por el requisito de los sofisticados tratamientos matemáticos (ecuaciones diferenciales) que habrían limitado su aplicación más allá de las ciencias físicas.

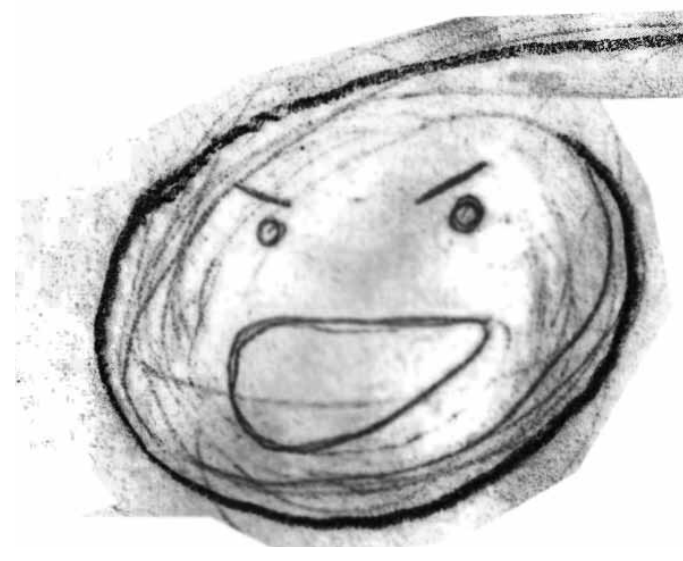

Aunque se trata de un software que permite representaciones harto descriptivas de los fenómenos estudiados, el SSG permitiría aproximaciones analíticas nada despreciables. Hollenstein identifica dos grandes tipos de estudios, cada uno de los cuales considera abordajes específicos en los que el aprovechamiento del SSG puede ser promisorio: estudios comparativos (en tiempo real) y estudios longitudinales (en tiempo real y tiempo del desarrollo).

Los primeros considerarían varias aproximaciones. Menciona el "análisis de regiones": "un abordaje de recurrente en el estudio de los patrones estables de comportamiento es empezar con una definición a priori de un estado atractor y una medida del grado en el cual un sistema se estabiliza en ese estado" (Hollenstein, 2007, p.386-87). Hollenstein (2007) sugiere que un estudio puede ocuparse de medir la fuerza de tal atractor (estado) examinando y analizando la duración y la frecuencia de un comportamiento respecto a una celda o un conjunto de celdas. Constituye un modo de testear y examinar una hipótesis o modelo apriorístico, contrastándolo con la fuerza de atracción de las celdas y regiones que, en principio, definen y calzan con la hipótesis. Otro abordaje comparativo lo constituye lo Hollenstein (2007) denomina "análisis de la totalidad de la rejilla". En este caso se trata de examinar el comportamiento a través del conjunto de la rejilla, y no sólo respecto a una región o celda. El énfasis en el análisis del conjunto de la rejilla es particularmente útil cuando se trata de examinar la variabilidad y flexibilidad de un sistema. En estos casos, no será la fuerza de atracción de una región o una celda, sino el número o rango de celdas visitadas, esto es, el rango y número de estados de comportamiento, la dispersión de los comportamientos en la grilla, el número de transiciones entre celdas y regiones o la tendencia a permanecer en un número pequeño de estados, los factores y elementos que se tendrán en cuenta. El grado de flexibilidad o la rigidez del sistema se expresará como dispersión o concentración de los recorridos en varias o en unas pocas celdas. Un tercer enfoque de este tipo de estudios comparativos son lo que Hollenstein (2007) llama "análisis de grupo", útil cuando se trata de hacer seguimiento no de individuos o diadas. En estos casos, no se examinan trayectorias, sino - por ejemplo- número de interacciones entre, por ejemplo, tipos de niños y niñas en un entorno escolar. En estos casos, "SSG puede ser usado para disponer información acerca de la distribución de valores en una matriz" (Hollenstein, 2007, p.389). 
Por otro lado, están los estudios longitudinales. En estos casos, resulta promisorio el uso del Space State Grid para desarrollar varios tipos de análisis. En primer lugar, el "análisis de atractores", esto es, de estados que tienen mayor probabilidad de ocurrencia que otros estados. Este tipo de análisis puede permitir identifica la región o celda atractor, medir su fuerza y examinar su estabilidad. La recurrencia en el pasaje de ciertas trayectorias por ciertas celdas y regiones, la duración o permanencia de tales eventos en esa celda o región y la duración de tal región en su capacidad de atraer trayectorias se pueden apreciar mediante SSG. Para ello resultan útiles algunas medidas que ofrece el propio software como número de transiciones y visitas por celda, tiempo o cantidad de retornos a las celdas examinadas. En segundo lugar, el análisis de las "transiciones de fase del desarrollo" puede ser muy fructífero a través de SSG, esto es, los momentos en que los patrones de un sistema son reorganizados de una nueva manera, atendiendo a las dos formas en que la variabilidad puede presentarse y representarse en SSG: como un incremento de la dispersión (aumento inusitado del número de celdas visitados) o como un incremento de las transiciones (incremento inusitado del número cambios entre celdas). Finalmente, Hollenstein (2007) sugiere un tipo de análisis o medida cuya utilidad puede ser importante: se trata del análisis del cambio y distancia entre rejillas, que proceden de diferentes momentos en el tiempo.

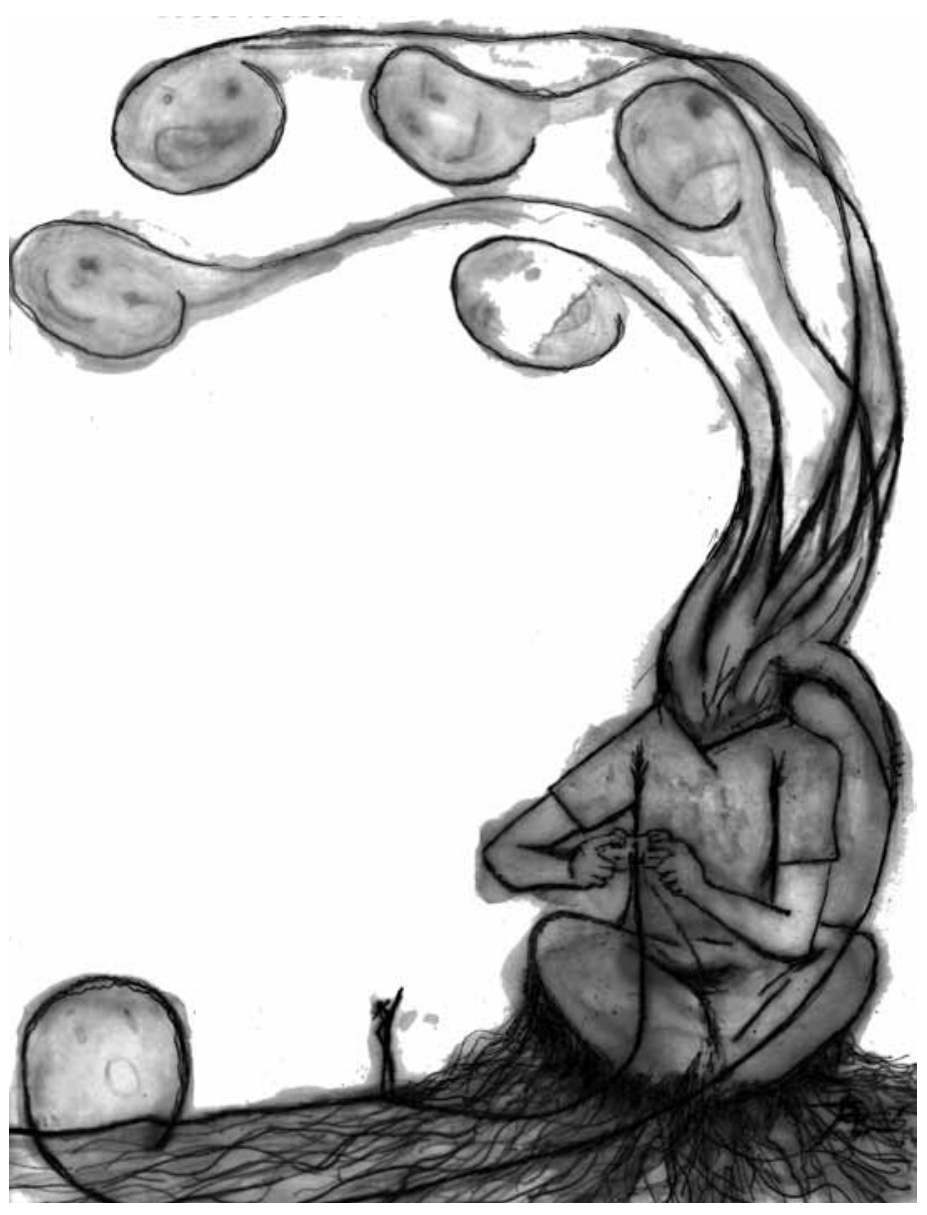

\section{Inestabilidad/Estabilidad en el sistema SVJ: pasajes TAD y TES en contraste}

En el futuro, nuestro estudio considerará análisis de distancia entre grillas o entre diferentes SVJ experimentadas por un videojugador y de las transiciones de fase en la actividad de videojuego, la relación entre momentos de mayor inestabilidad del sistema SVJ y emergencia de soluciones y descubrimientos para la resolución de las tareas de videojuego. Por lo pronto, en este artículo, nos ocuparemos de contrastar y comparar el comportamiento conjunto de los estados emocionales, elocutivos y corporales durante las tareas de mayor dificultad (TAD) con aquellos que se presentan durante las tareas de estándar (TES) o de menor dificultad en la SVJ.

Estamos suponiendo que tanto las dinámicas corporales como los flujos emocionales, junto a las elocuciones self (Obando \& González, 2008b y 2010), sirven para extender, de manera virtual, el tiempo de resolución de la tarea, automatizar procedimientos y jalonar hallazgos y soluciones inesperadas. Cuando las automatizaciones y la lógica no son suficientes para tratar una tarea las derivas emocionales, elocutivas y corporales desentraban, por así decirlo, su tratamiento. Podemos presentar este planteamiento de manera muy esquemática y simple. Imaginemos un polígono (de fuerzas) con cuatro vectores: cognición, emoción, acción y percepción. Cuando se presenta una tarea que tiende a demandar más participación de uno de los vectores, por ejemplo, una tarea de percepción multiestable -como la que ofrece Varela (1999, 2000)-, o cognitiva-como las que suelen encontrarse en los estudios piagetianos- o de coordinación motora como las que examinaba Thelen (1986, 1991, 1993), o emocional, como las que se usan en los estudios sobre juicio moral, empatía o reconocimiento de estados emocionales (Harris, de Rosnay \& Pons, 2005), los otros tres vectores se convierten en "sistema de recursos" dinámico para resolver la tarea cuando los recursos próximos (esto es, los más cercanos a la tarea) no son suficientes o no están disponibles. Por ejemplo: debo levantar un peso extraordinario y recurro al grito y a la reducción o dulcificación del tamaño y la ubicación de una mejor manera de soportarlo, para poder realizar la operación; o tengo una tarea cognitiva no abarcable de manera lógica, y apelo a recursos emocionales, corporales y preceptúales para operarla. Contraigo los músculos de los ojos para resolver una tarea perceptual. Y así sucesivamente. Sólo cuando los recursos próximos al tipo de tarea están disponibles (esto es, han sido automatizados), es decir, tengo la capacidad mental, corporal, perceptual, emocional para tratarlos, los otros se convierten en subsidiarios, laterales o marginales. 
Para efectos de análisis tenemos las siguientes distinciones operativas básicas. Hay cuatro tipos de videojuegos (González \& Obando, 2008a y 2010) realizadas a partir de conceptos claves derivados de Levy (1999), videojuegos en que se realizan elecciones o videojuegos de realización, videojuegos en que se organizan recursos o videojuegos de potenciación, videojuegos en que se resuelven problemas o videojuegos de actualización, y videojuegos en que se crean recursos, mundos y problemas, o videojuegos de virtualización. Respecto a las restricciones de tiempo para resolver las tareas que impone un videojuego, tenemos que habría videojuegos sin restricciones temporales o de Tiempos Amplios (TA) de resolución de la tarea, y videojuegos con restricciones temporales o de Tiempos Estrechos (TE) de resolución de la tarea. Hemos clasificado cinco estados emocionales del videojugador en la SVJ: negativo (cansancio, rechazo, aburrimiento), negativo + (excitación, frustración con deseos de continuar el juego, expectativa y tensión), neutro (estado de dominio pleno del juego, ni excitación, ni aburrimiento), positivo (alegría, entusiasmo durante el curso del videojuego) y positivo + (euforia, celebración, alta excitación asociada a celebración). Hemos considerado siete (7) estados elocutivos: self-GET o elocuciones en que el videojugador habla de sí mismo como si fuera un personaje del mundo del videojuego, esto es, como si estuviera situado en el plano temporal de los eventos del mundo ficcional del videojuego (GET por Game Event Time); self-PET o elocuciones en que el videojugador habla de sí mismo en su condición de videojugador o como si estuviera situado en el plano temporal de los eventos relacionados con el jugar (PET por Play Event Time); y elocuciones self-SET, en que el videojugador habla de sí mismo en calidad de persona o sujeto inscrito en el plano temporal del mundo social (SET por Social Event Time). También hay elocuciones referidas al videojuego, sin constituir elocuciones self (ref-vj), elocuciones no referidas al videojuego (no-ref-vj), hay elocuciones no clasifibles, y pasajes sin elocuciones (SF). Y finalmente, hemos diferenciado siete estados, posiciones o reacomodos corporales: acostado bocabajo y sus variantes, acostado de medio lado y sus variantes, acostado bocarriba y sus variantes, sentado en posición de loto y variantes, sentado estándar y variantes, sentado de medio lado y variantes, arrodillado y variantes, parado. Se registran bajo la denominación otra posición aquellas que no se ajustan a ninguna de las que hemos definido y determinado. Adicionalmente se consideran los RAM (reacomodos corporales menores), que consisten en movimientos repetitivos, rápidos, rítmicos y breves, localizados en alguna parte específica del cuerpo, en especial, la cabeza y extremidades.
Para efectos de análisis tenemos las siguientes distinciones operativas básicas. Hay cuatro tipos de videojuegos (González \& Obando, 2008a y 2010) realizadas a partir de conceptos claves derivados de Levy (1999), videojuegos en que se realizan elecciones o videojuegos de realización, videojuegos en que se organizan recursos o videojuegos de potenciación, videojuegos en que se resuelven problemas o videojuegos de actualización, y videojuegos en que se crean recursos, mundos y problemas, o videojuegos de virtualización. Respecto a las restricciones de tiempo para resolver las tareas que impone un videojuego, tenemos que habría videojuegos sin restricciones temporales o de Tiempos Amplios (TA) de resolución de la tarea, y videojuegos con restricciones temporales o de Tiempos Estrechos (TE) de resolución de la tarea. Hemos clasificado cinco estados emocionales del videojugador en la SVJ: negativo (cansancio, rechazo, aburrimiento), negativo + (excitación, frustración con deseos de continuar el juego, expectativa y tensión), neutro (estado de dominio pleno del juego, ni excitación, ni aburrimiento), positivo (alegría, entusiasmo durante el curso del videojuego) y positivo + (euforia, celebración, alta excitación asociada a celebración). Hemos considerado siete (7) estados elocutivos: self-GET o elocuciones en que el videojugador habla de sí mismo como si fuera un personaje del mundo del videojuego, esto es, como si estuviera situado en el plano temporal de los eventos del mundo ficcional del videojuego (GET por Game Event Time); self-PET o elocuciones en que el videojugador habla de sí mismo en su condición de videojugador o como si estuviera situado en el plano temporal de los eventos relacionados con el jugar (PET por Play Event Time); y elocuciones self-SET, en que el videojugador habla de sí mismo en calidad de persona o sujeto inscrito en el plano temporal del mundo social (SET por Social Event Time). También hay elocuciones referidas al videojuego, sin constituir elocuciones self (ref-vj), elocuciones no referidas al videojuego (no-ref-vj), hay elocuciones no clasifibles $^{2}$, y pasajes sin elocuciones (SF). Y finalmente, hemos diferenciado siete estados, posiciones o reacomodos corporales: acostado bocabajo y sus variantes, acostado de medio lado y sus variantes, acostado bocarriba y sus variantes, sentado en posición de loto y variantes, sentado estándar y variantes, sentado de medio lado y variantes, arrodillado y variantes, parado. Se registran bajo la denominación otra posición aquellas que no se ajustan a ninguna de las que hemos definido y determinado. Adicionalmente se consideran los RAM (reacomodos corporales menores), que consisten en movimientos repetitivos, rápidos, rítmicos y breves, localizados en alguna parte específica del cuerpo, en especial, la cabeza y extremidades. 
Nuestra hipótesis es que ante pasajes TAD, con Videojuegos TE (de realización y potenciación), deberían presentarse tanto mayor actividad corporal, incluidos movimientos RAM, como elocutiva. Lo que no debería presentarse son posiciones estables duraderas y pocas elocuciones self, a menos que -complementariamente- esta posición estable considere alguna forma de rigidización (que equivale a un dinámica masiva de RAM a lo largo del cuerpo), acompañada de un estado emocional Negativo +. No parece probable en un pasaje TAD de videojuego un estado cero: posición corporal estable, ningún evento RAM, cero elocuciones self y estado emocional neutro.

Para verificar esta hipótesis se hace preciso comparar las configuraciones que se presentan en los pasajes TAD y TES de la SVJ examinada, teniendo en cuenta diferencias en los tipos de videojuegos y en los tiempos de resolución que suponen y demandan. Es esperable que se presente mayor inestabilidad elocutiva, corporal y emocional en un tramo TAD que en unoTES, en un tramo TE que en uno TA, y en un videojuego de resolución de problemas que en uno de realización o potenciación. Se espera que la combinación TAD + TE sea particularmente propicia a un rango mayor de inestabilidad elocutiva, corporal y emocional, que la combinación TES+TA. Es razonable esperar significativa estabilidad en un tramoTES+TA de un videojuego de realización, mientras parece esperable una mayor inestabilidad en un tramo TAD+TA del mismo tipo de videojuego.

En esta ocasión estudiamos la misma situación estudiada en el artículo publicado en este número de la revista. Se trata de una situación de videojuego en que participó el niño HMG (7:1), un niño que no presenta problemas de motricidad, ni limitaciones comprobadas de aprendizaje y comprensión de las tareas escolares, equilibrado emocional y afectivamente, y que vive y crece en una ciudad intermedia en Colombia (Popayán), en un entorno urbano de clase media y en una familia de la que recibe protección, estímulo y educación escolar de buena calidad. La SVJ se desarrolló durante el mes de junio de 2009 y se prolongó por casi 3 horas. El registro consideró 17720 unidades de 10 segundos. Durante la SVJHMG120609³ el niño jugó con una consola XBOX 360 y usó los siguientes videojuegos: San Andreas, Ladrón de Autos (videojuego de realización TA y TE ${ }^{4}$, y de actualización), The House of the Death II (videojuego de realización TA y TE), Bloody Road Extreme y Kyrby (videojuegos de realiza-

ción TA, TE y de potenciación TE), Tetrisport

(videojuego de potenciación TE), Mario Bros. y Rey León (videojuegos de realización TA y TE).

Para efectos de análisis vamos a considerar el lapso que va de la unidad 710 a la $10720^{5}$. A continuación, se organizan los tipos de videojuegos de la SVJHG061209, dispuestos de mayor a menor estabilidad (elocutiva, corporal y afectiva) esperada. Se indica el número de unidades de 10 segundos que, en la SVJ, corresponden a cada tipo de videojuego. También el tipo de restricciones temporales para la resolución de la tarea de videojuego y el tipo de dominio o relación que el videojugador ejerce sobre la tarea (TAD o TES).

\begin{tabular}{clll}
\hline $\begin{array}{c}\text { Organizados } \\
\text { de mayor a } \\
\text { menor } \\
\text { estabilidad } \\
\text { esperada }\end{array}$ & Tipo de Videojuego & $\begin{array}{c}\text { Relación } \\
\text { con la } \\
\text { Tarea }\end{array}$ & $\begin{array}{c}\text { Número de } \\
\text { Unidades de 10 } \\
\text { Segundos que } \\
\text { contienen este tipo } \\
\text { de eventos }\end{array}$ \\
\hline 1. & Realización TA & TES & 274 \\
2. & Potenciación TA & TES & 0 \\
3. & Realización TE & TES & 119 \\
4. & Potenciación TE & TES & 0 \\
5. & Actualización (TA) & TES & 41 \\
6. & Virtualización (TA) & TES & 0 \\
7. & Realización TA & TAD & 122 \\
8. & Potenciación TA & TAD & 0 \\
9. & Realización TE & TAD & 90 \\
10. & Potenciación TE & TAD & 112 \\
11. & Actualización (TA) & TAD & 38 \\
12. & Virtualización (TA) & TAD & 0 \\
& Total de Unidades de & & 796 \\
\hline
\end{tabular}

\section{Tabla 8 Distribución de tipos de videojuegos y tipos de relación con la tarea en la SVJ estudiada.}

Como puede apreciarse es posible establecer comparaciones entre videojuegos de realización con diferentes tipos de tiempo de resolución y distintas maneras de relacionarse el videojugador con ellos. Es posible contrastar también las configuraciones que se presentan en estos casos, con aquellas que emergen en los videojuegos de actualización. No hay pasajes que incluyan videojuegos de virtualización, y sólo contamos con registros de videojuegos de potenciación para la variante de Tiempos Estrechos de resolución yTarea de Alta Dificultad. La primera pregunta que vale la pena hacer es cómo se distribuyen y qué porcentaje de unidades de tiempo de 10 segundos consideran eventos TAD y eventos TES, y de qué manera se presentan los estados elocutivos, emocionales y las reorganizaciones corporales en cada uno de los dos tipos de eventos. Veamos a continuación este registro. 


\begin{tabular}{|c|c|c|}
\hline Distribución de Eventos TAD y Tes & TAD & TEs \\
\hline $\begin{array}{c}\text { Total de Unidades de 10 segudos con } \\
\text { presencia de Eventos TAD }\end{array}$ & 360 & 429 \\
\hline $\begin{array}{c}\text { Porcentaje Eventos con } \\
\text { Elocuciones Articuladas a Videojuego } \\
\text { (self y referidas) }\end{array}$ & $23,61 \%$ & $39,16 \%$ \\
\hline $\begin{array}{c}\text { Porcentaje de Eventos RAM } \\
\text { Porcentaje de Eventos } \\
\text { Estados Emocionales } \\
\text { No Neutros }\end{array}$ & $24,17 \%$ & $11,19 \%$ \\
\hline & $89,72 \%$ & $53,85 \%$ \\
\hline
\end{tabular}

\section{Tabla 9 Distribución de Eventos TAD y TES en la SVJHMG120609.}

Los estados emocionales no neutros y los eventos RAM son significativamente mayores en las secuencias TAD. Sin embargo la actividad elocutiva articulada a la dinámica del videojuego (elocuciones self y elocuciones referidas) en las secuencias TAD es casi la mitad de la actividad elocutiva del mismo tipo en las secuencias TES. De todos modos, en estos registros están entremezclados datos de diferentes tipos de videojuegos y con restricciones temporales variadas. Nos interesa describir qué ocurre con la distribución de eventos cuando el tiempo de resolución de la tarea se contrae, esto es, qué pasa cuando se trata de videojuegos de realización y potenciación TE, respecto a sus variantes TA, y respecto a los videojuegos de virtualización y actualización, cuyo rasgo más frecuente es el Tiempo Amplio de resolución.

Presentamos a continuación los resultados encontrados para cada uno de los tipos de videojuego. Los expondremos empezando por los segmentos o tramos de la SVJ en que se esperaría menor inestabilidad en los estados emocionales, corporales y elocutivos, y terminando en aquellos en que se esperaría mayor inestabilidad. Para la presentación consideraremos tres rejillas por tramo o segmento de la SVJ estudiada. Las tres rejillas, generadas a través de Gridware (Lamey, Hollenstein, Lewis \& Granic, 2004), consideran en el eje $\mathrm{X}$ la relación TAD o TES con la tarea y en el eje Y, los reacomodos corporales, los estados emocionales y los estados elocutivos, respectivamente.

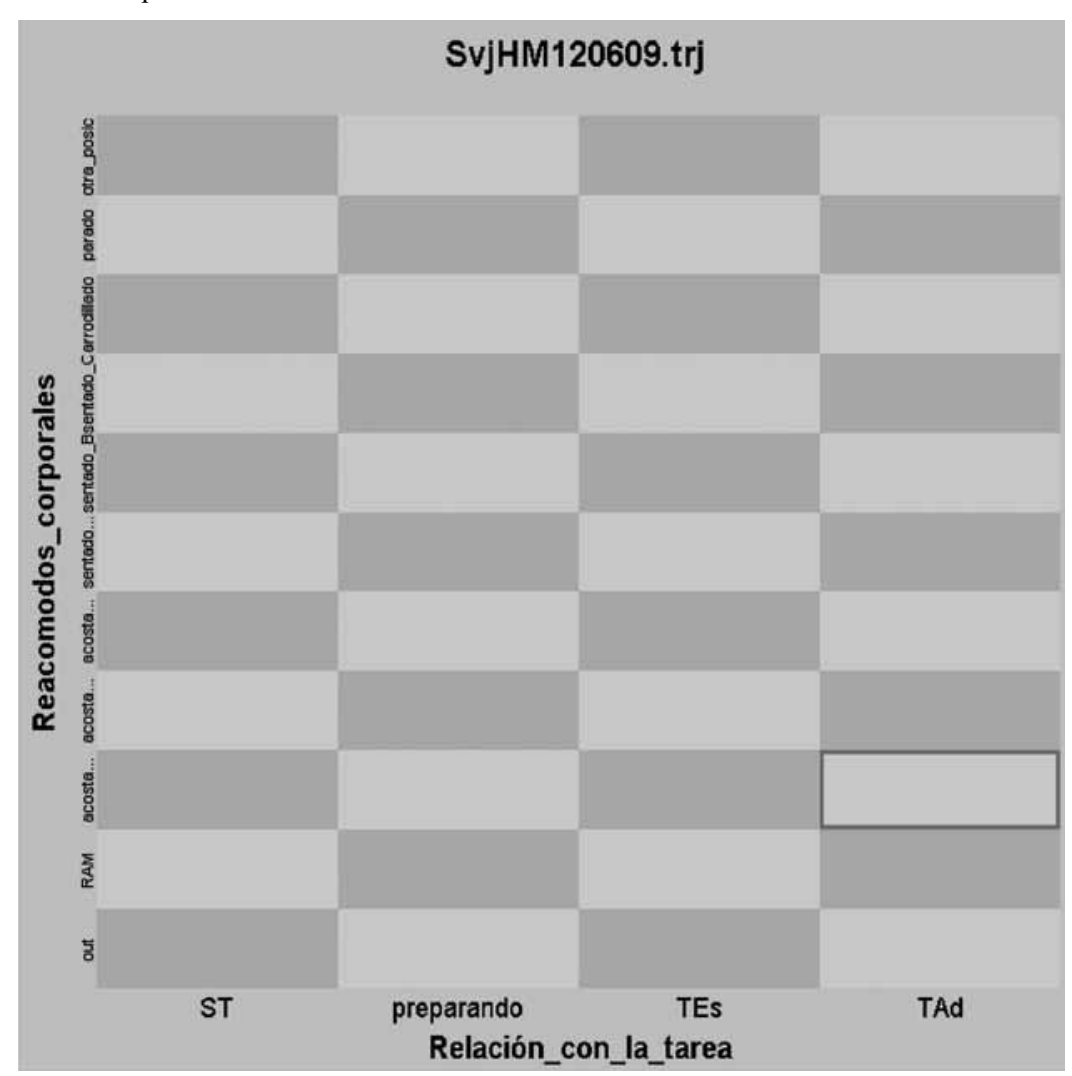

Gráfico. Rejilla de Reacomodos Corporales en relación con la Tarea. En el eje X, los estados de relación con la tarea de videojuego: $S T$, sin tarea, indica que el videojugador está en estado de No Juego; preparando, refiere a que la consola de videojuego está cargando archivos, presentando repetición del videojuego previo o presentando los créditos y autorías del videojuego. TES: Tarea Estándar o de baja dificultad para el videojugador; TAD: Tarea de Alta Dificultad para el videojugador. En el ejeY, los diferentes estados corporales: out (el videojugador está fuera de la SVJ), RAM (Reacomodo Corporal Menor); tres estados corporales estables en posición de acostado; dos estados corporales estables en posición de sentado; posición de arrodillado; posición de parado, $y$, finalmente, otras posiciones que no se ajustan a esta clasificación. 


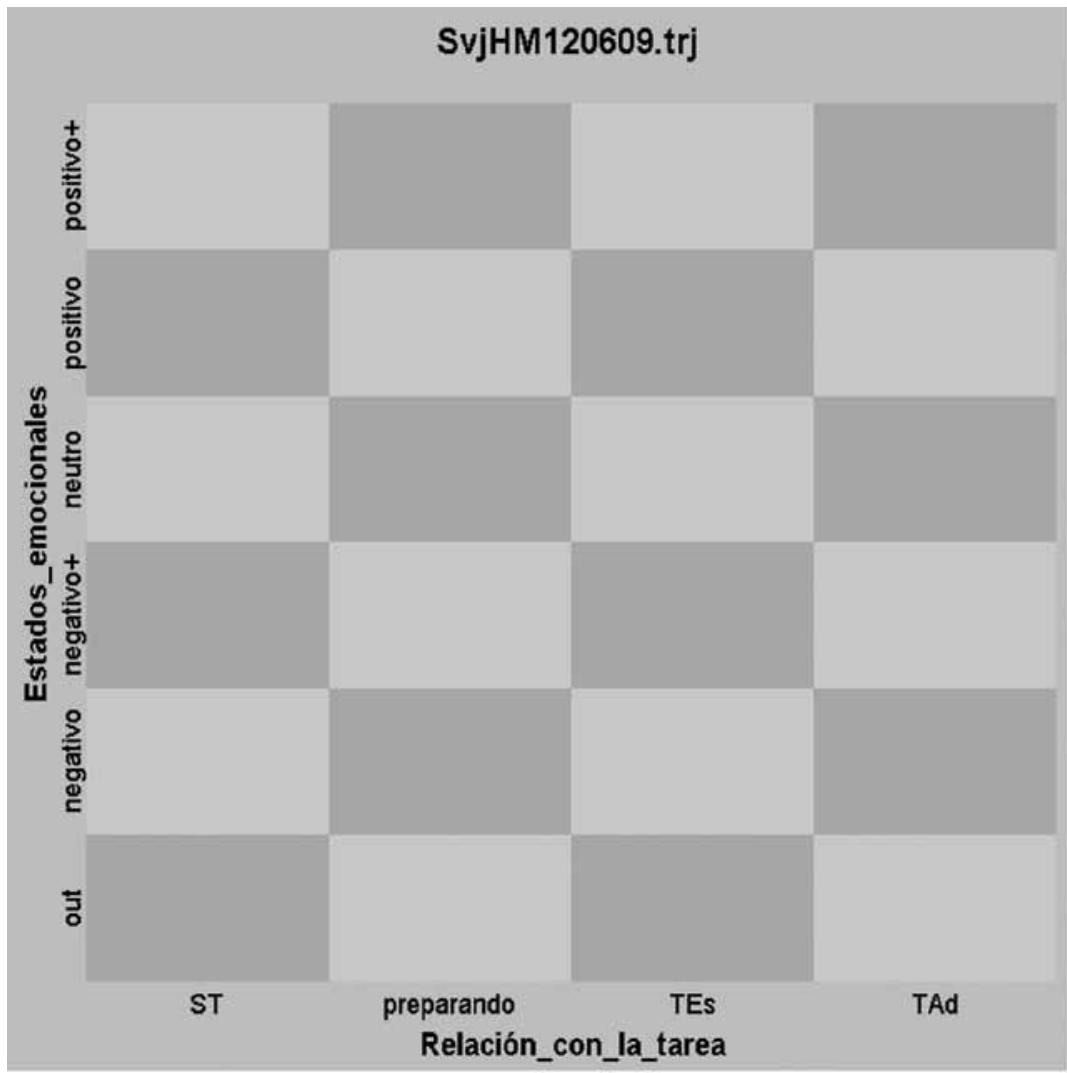

Gráfico . Rejilla de Estados Emocionales en relación con la Tarea. Los descriptores del eje $Y$ (estados emocionales) son los siguientes. Out: el videojugador está ausente de la SVJ, negativo (aburrido), negativo + (excitado expectante), neutro (estable), positivo (alegre), negativo + (excitado eufórico).

Gráfico Rejilla Estados de Elocución en Relación con la Tarea. A continuación, los descriptores del ejeY (Estados de Elocución). Out (el videojugador está ausente de la SVJ), SE (Sin Elocución), No-Refer-Vj (Elocución no referida el videojuego), Refer-Vj (elocución referida al videojuego), $y$ elocuciones self (self-SET, self-PET y self-GET).

Cada unidad de 10 segundos en la que se presentan eventos ajustados a los descriptores mencionados, se grafica como un punto en rejilla. La rejilla también permite presentar la trayectoria o secuencia de eventos, interconectados y representados gráficamente con flechas ( ), tal como se podrá observar en las gráficas sigmientes.

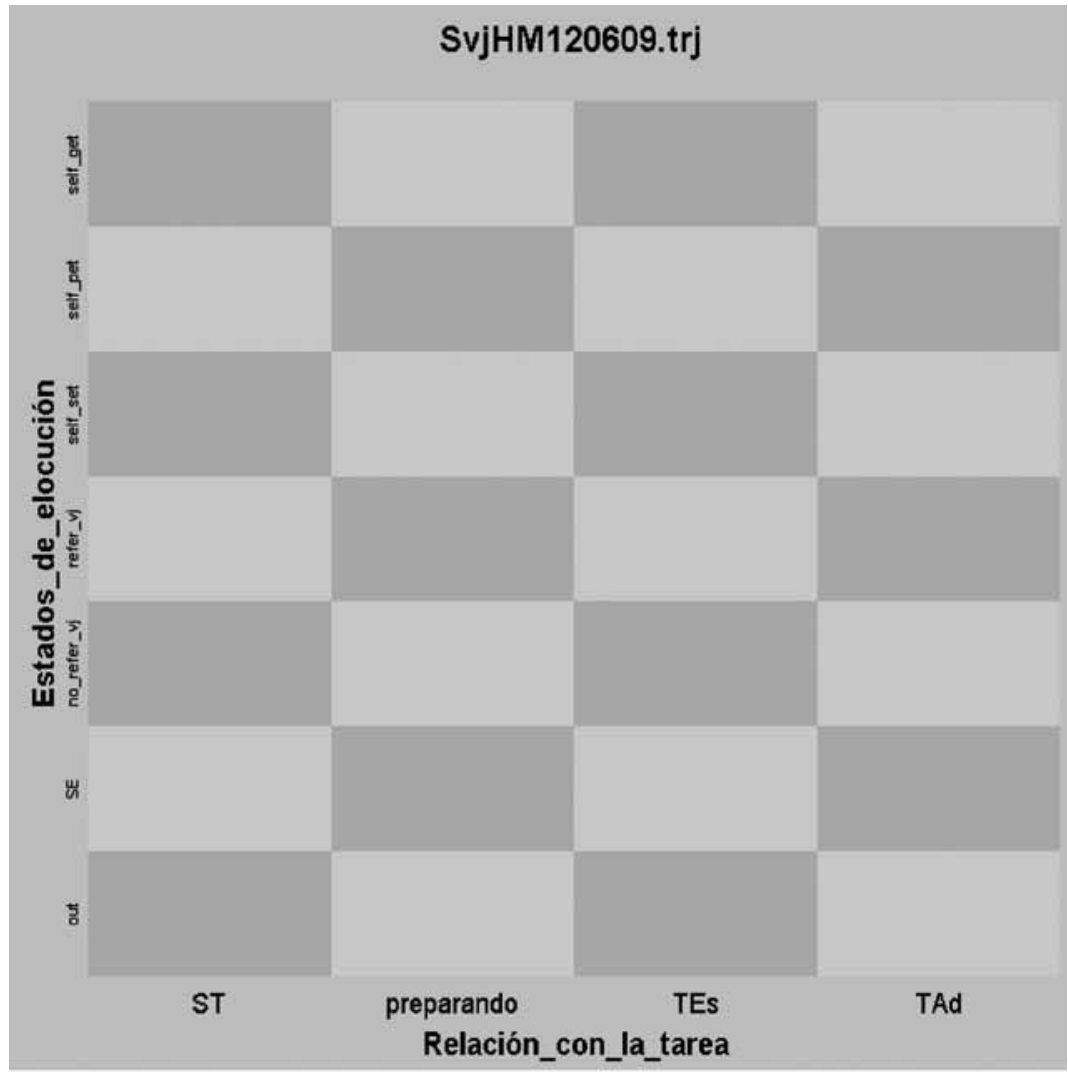




\section{Tramos de Videojuegos de Realización y Potenciación TA/TES}

Lo esperable en estos tramos de la SVJ sería una significativa estabilidad, debido a que no hay restricciones en los tiempos de resolución de la tarea (Tiempos Amplios), hay dominio rutinario del videojuego (TES) y no se trata de videojuegos complejos. En el estudio se presentaron 261 unidades de 10 segundos en las que se presenta este tipo de condiciones ${ }^{6}$, distribuidas en 26 tramos. El rango de duración de los tramos está entre 3 y 22 unidades de 10 segundos. Se presentaron tanto tramos con importante estabilidad en el comportamiento de los estados emocionales, corporales y elocutivos, como tramos con significativa inestabilidad, lo que desafía la hipótesis. En un 36,5\% de la unidades analizadas se presenta un comportamiento estable, es decir, ajustado a lo que se esperaría en el modelo o hipótesis planteada; en un 37\% de las unidades analizadas se encontró significativa inestabilidad, lo que controvierte el modelo; y en un $26,3 \%$ se encontraron comportamientos mixtos (inestabilidad de algunos de los estados y estabilidad en otros), es decir, parcialmente ajustados a lo que se esperaría en el modelo. A continuación una ilustración tanto de comportamientos que se ajustan al modelo, como de aquellos que lo controvierten parcial o completamente.

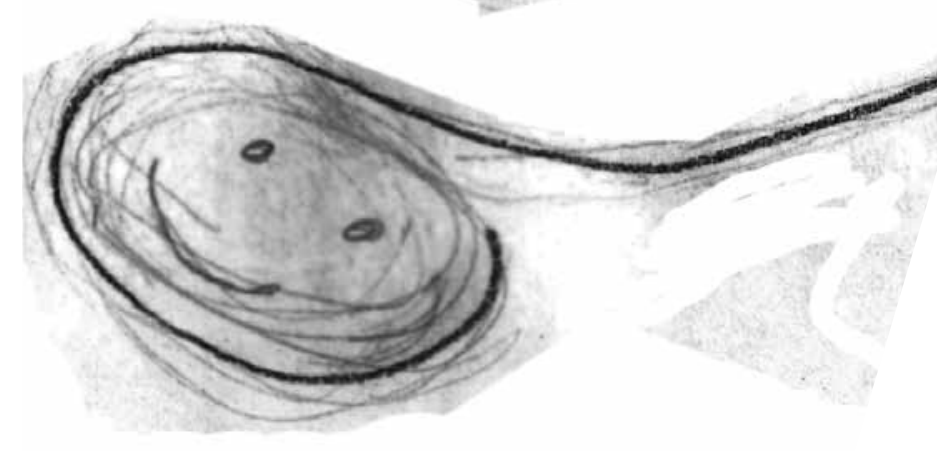

Tramo 10590-10720 (14 unidades de 10 segundos).

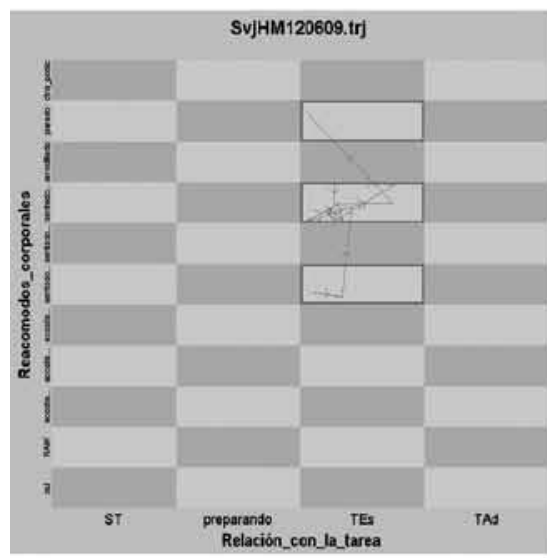

Reacomodos corporales

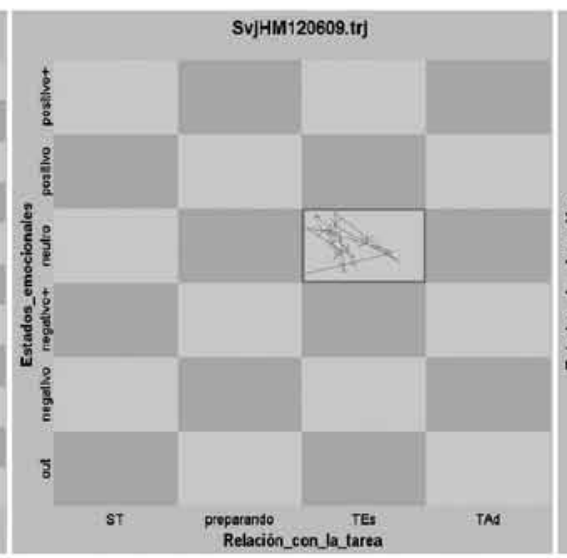

Estados emocionales

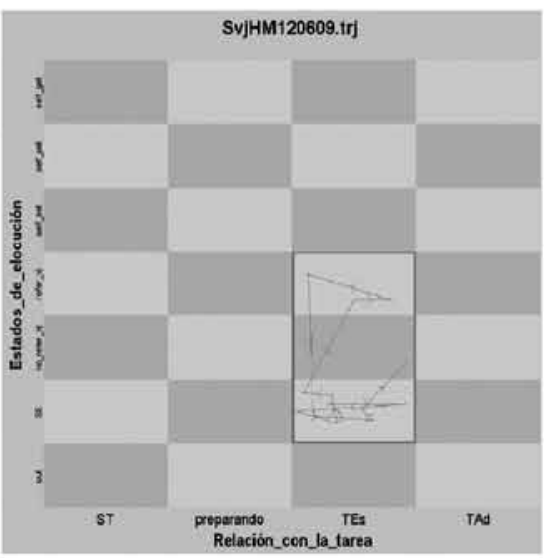

Estados Elocutivos

\section{Gráfico 4. Tramo con comportamientos} ajustados al modelo.

El comportamiento es significativamente estable en este

tramo de la SVJ. Se ajusta a lo que se esperaría en un videojuego sencillo (de realización o potenciación), en el que el videojugador a alcanzado dominio y cierto nivel de automatización de los procedimientos y operaciones (Tarea Estándar) y no hay restricciones de tiempo para resolver el videojuego (Tiempo Amplio). No hay eventos RAM, el sujeto adopta tres posiciones corporales estables; permanece en un estado emocional neutro y la actividad elocutiva es baja, sin presencia de eventos elocutivos self, que se señalarían una mayor implicación emocional con el desarrollo del videojuego. 
Tramo 6840-7020 (18 unidades de 10 segundos)

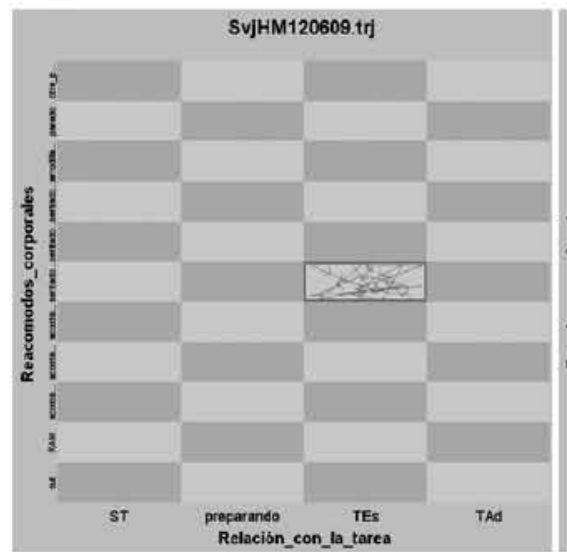

Reacomodos corporales

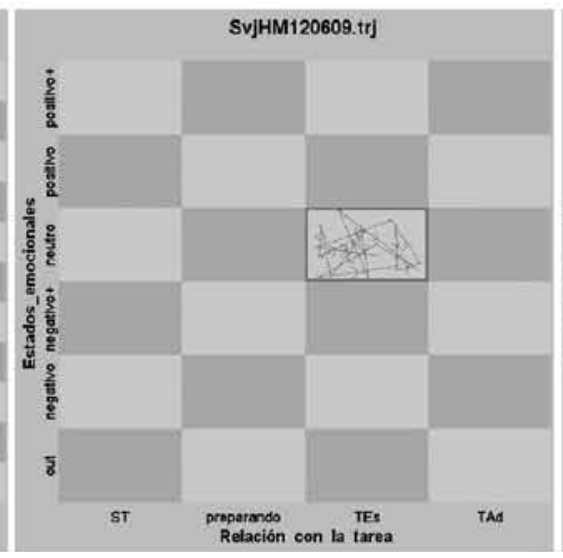

Estados emocionales

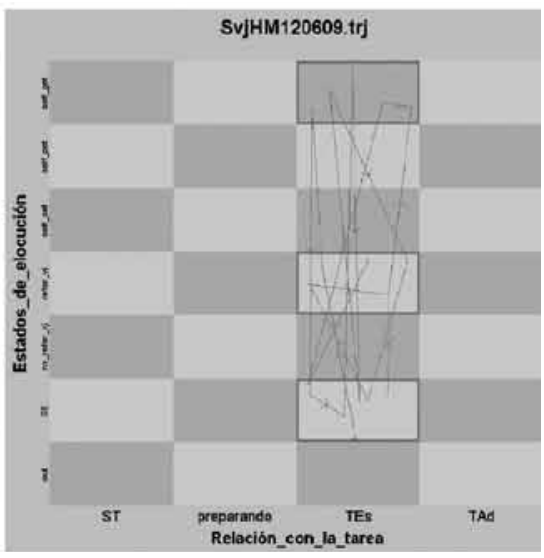

Estados Elocutivos

\section{Gráfico 5. Tramo con comportamientos} parcialmente ajustados al modelo.

Aunque hay comportamiento emocional y corporalmente estable, se aprecia significativa inestabilidad elocutiva, con importante presencia de eventos elocutivos self-GET. Este pasaje se ajusta sólo parcialmente al modelo.

Tramo 2850-3010 (17 unidades de 10 segundos)

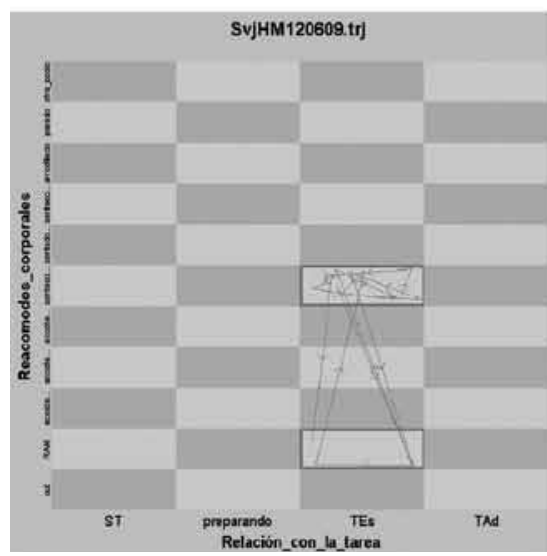

Reacomodos corporales

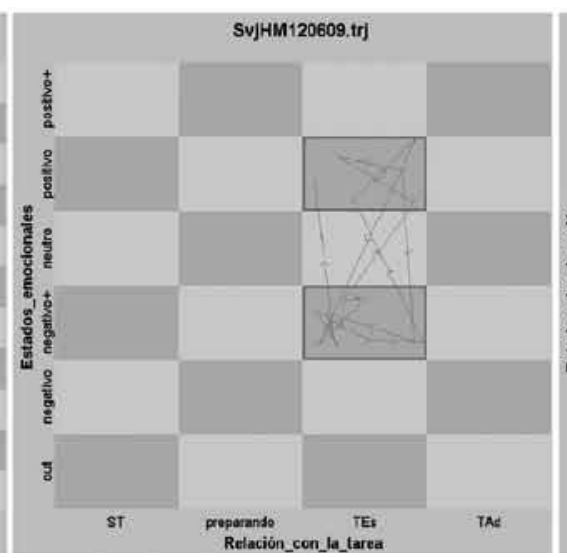

Estados emocionales

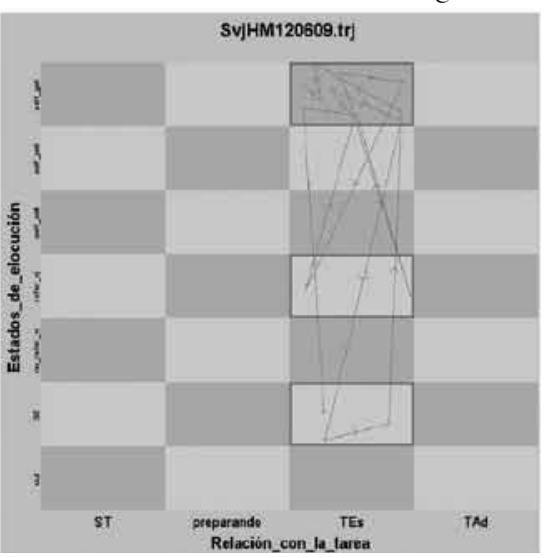

Estados Elocutivos

Gráfico 6. Tramo con comportamientos no ajustados al modelo.

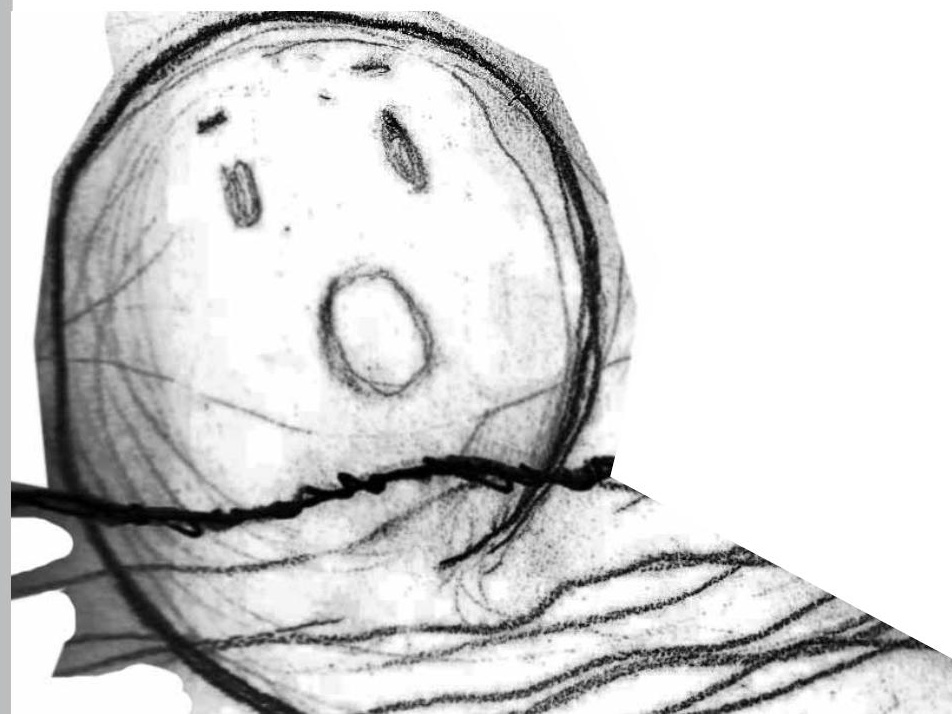

Además de la presencia de eventos RAM, el sujeto permanece expectante y excitado (negativo + ) a lo largo de este tramo de la SVJ y hay una importante presencia de elocuciones self-GET. 


\section{Tramos de Videojuegos de Realización y Potenciación TE/TES}

Es esperable una menor estabilidad en estos pasajes que en los anteriores. La única restricción fuerte es el tiempo (TE); pero la simplicidad de la tarea (videojuego) y el hecho de que se trata de tramos de rutina, hacen esperable formas intermedias de inestabilidad. Es decir, no se trata de la estabilidad generalizada de los videojuegos de realización y potenciación TA+TES, que deberían constituir la forma más estable del sistema. Es esperable también que la inestabilidad TE + Videojuegos de realización y potenciación, sea menor que la inestabilidad en los casos TAD en cualquiera de las variantes de videojuego, dado que las características de la relación con el videojuego (TAD y TES) constituye el principal vector de inestabilidad, seguido del tipo de videojuego y de las restricciones temporales para la resolución del videojuego. La complejidad del videojuego, en sí mismo, en tanto produzca dinámicas TAD es suficientemente inestable, incluso en los videojuegos TA. De esta manera, un videojuego de virtualización con TE y dinámica TAD debería producir la mayor inestabilidad del sistema.

En la SVJ analizada, se presentaron 119 unidades de 10 segundos con estas características, distribuidas en ocho tramos, cuyas duraciones se sitúan en rangos entre 9 y 22 unidades. Predominaron los tramos ajustados a lo que se esperaría en el modelo, esto es, una moderada inestabilidad del sistema, comportamientos mixtos en que, por ejemplo, una fuerte dinámica elocutiva esté acompañada de moderada o completa estabilidad en las posiciones corporales y el estado emocional. En general se encontró mayor estabilidad en estos tramos que en los anteriores. El 81,35\% de los tramos presenta y se ajusta al comportamiento esperado; el 18,65\% de los tramos presenta comportamientos parcialmente ajustados al modelo, y, finalmente, no hay ningún tramo que está claramente no ajustado al comportamiento esperado. A continuación, dos tramos que ilustran ambos tipos de circunstancias.

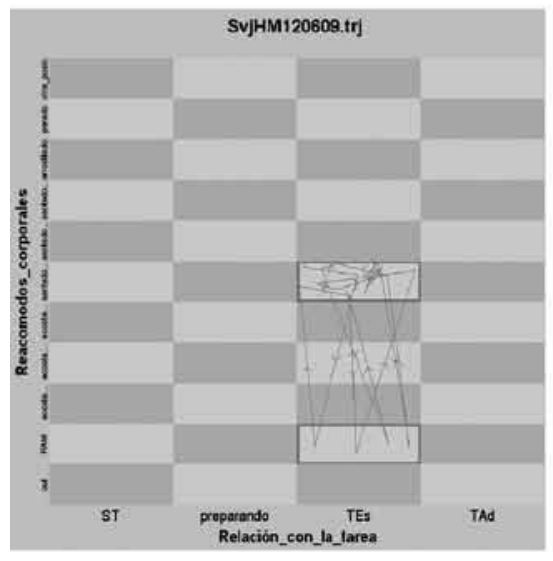

Reacomodos corporales

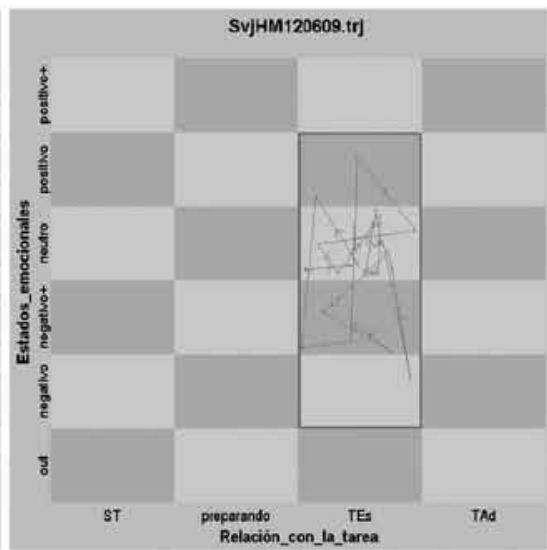

Estados emocionales
Tramo 5320-5530 (22 unidades de 10 segundos)

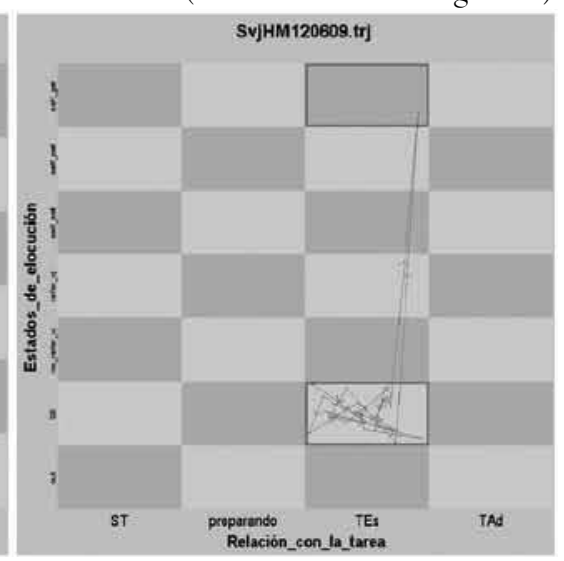

Estados Elocutivos

Gráfico 7. Tramo con comportamientos ajustados al modelo.

En el tramo se presenta importante inestabilidad corporal, con varios pasajes RAM, moderada inestabilidad emocional, significativa estabilidad elocutiva y un episodio elocutivo self-GET. 
Tramo 3920-4130 (22 unidades de 10 segundos)

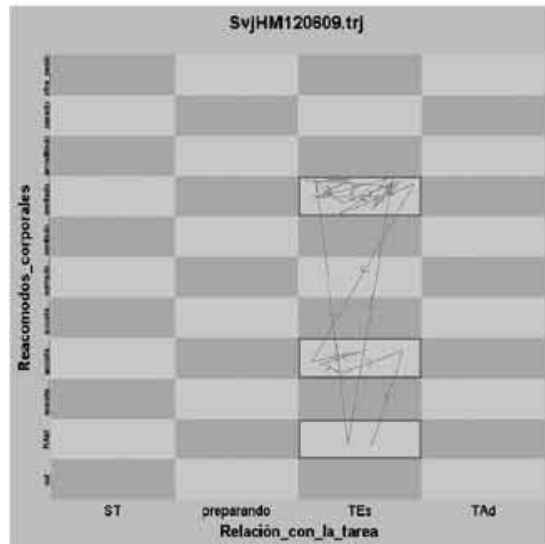

Reacomodos corporales

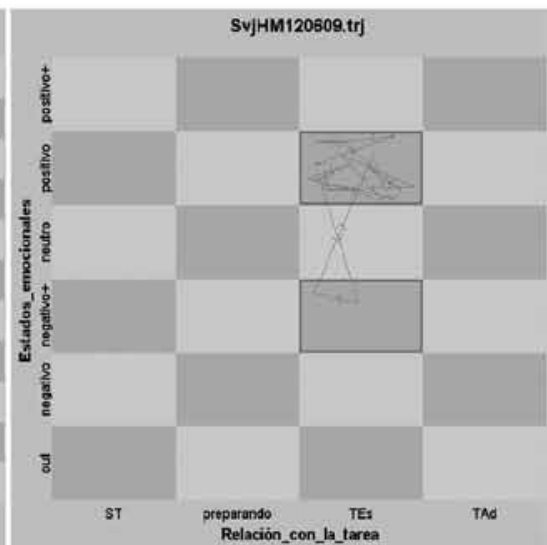

Estados emocionales

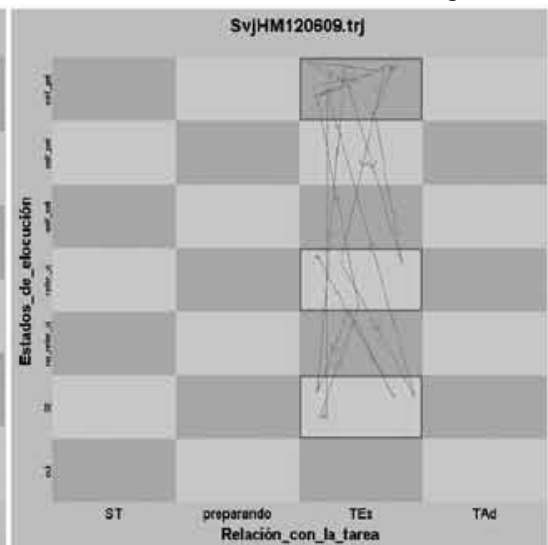

Estados Elocutivos

\section{Gráfico 8. Tramo con comportamientos parcialmente ajustados al modelo.}

\section{Tramos deVideojuegos de Actualización (TẢ)/TES}

Lo esperable en este caso es una dinámica combinada: por un lado, la complejidad del videojuego procura una suerte de deriva inestable; pero por otro lado, la relación con la tarea es TES, esto es, el videojugador a conseguido automatizar parte de los procedimientos de un videojuego complejo, lo que deja como resultado un escenario con baja complejidad debido al dominio que el videojugador ejerce sobre la tarea. Por lo tanto, lo esperable es una dinámica moderadamente estable, pero - en conjunto- mucho más inestable que los tramos anteriores, debido a la mayor complejidad del videojuego.

En la SVJ se presentaron 41 unidades (de 10 segundos) de este tipo. Se trata de un largo tramo de videojuego de actualización o resolución de problema, en el que el videojugador se desempeña con amplio dominio y experticia.Y en efecto, el conjunto del tramo se ajusta a los comportamientos esperados. Estabilidad corporal, con presencia marginal de eventos RAM, moderada estabilidad emocional e importante actividad elocutiva, incluido eventos self-GET. A continuación, ilustramos el tramo.

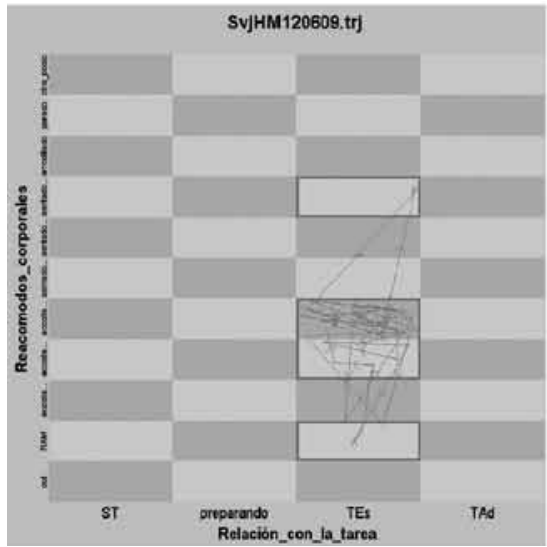

Reacomodos corporales

\section{Gráfico 9.}

Tramo con comportamientos ajustados al modelo.
Tramo 3180-3580 (41 unidades de 10 segundos)

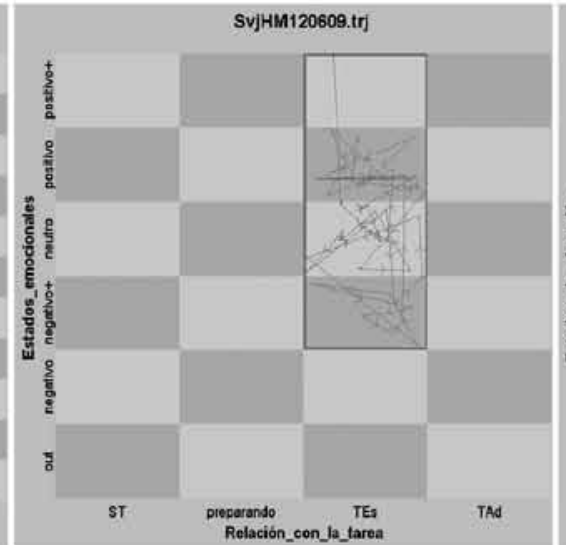

Estados emocionales

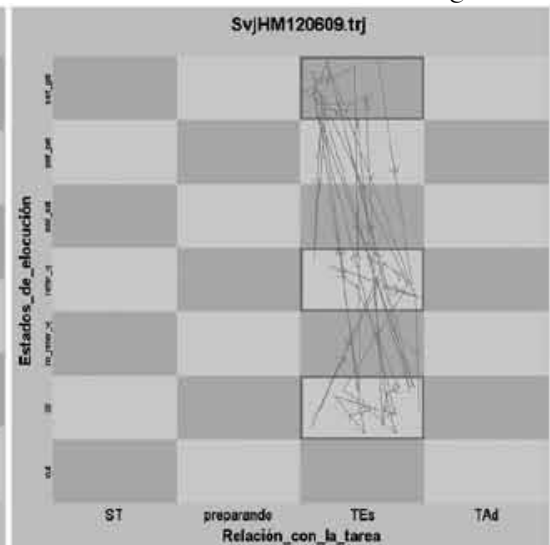

Estados Elocutivos
El tramo presenta estabilidad corporal, con un breve pasaje RAM y dos posiciones corporales estables; inestabilidad emocional moderada y fuerte inestabilidad elocutiva. La complejidad del videojuego arrastra la dinámica inestable, a pesar de tratarse de un videojuego TA en el cual el videojugador ejerce relativo dominio automatizado de la tarea. 


\section{Tramos de Videojuegos de Realización (TA)/TAD}

Los tramos presentados a continuación deberían ofrecer un aumento significativo de las inestabilidades virtud de la menor pericia y dominio del videojugador sobre el videojuego. La fuerza de la relación TAD constituye un factor que introduce profunda inestabilidad en la dinámica. Esa restricción puede ser moderada por la forma temporal de la tarea (TA). Lo esperable, en todo caso, son comportamientos claramente inestables, aunque no necesariamente continuos. Se presentaron 122 unidades de 10 segundos correspondientes a este tipo de videojuegos con relaciones TAD y Tiempo Amplio de resolución de la tarea. Estas unidades se distribuyen en seis tramos, con rangos entre cuatro y 60 unidades. El 100\% de los tramos se ajusta al comportamiento esperado. Predominó el comportamiento corporal estable, esto es, pocos eventos RAM, con intensa inestabilidad emocional y elocutiva. A continuación, un tramo que ilustra este tipo de comportamiento.

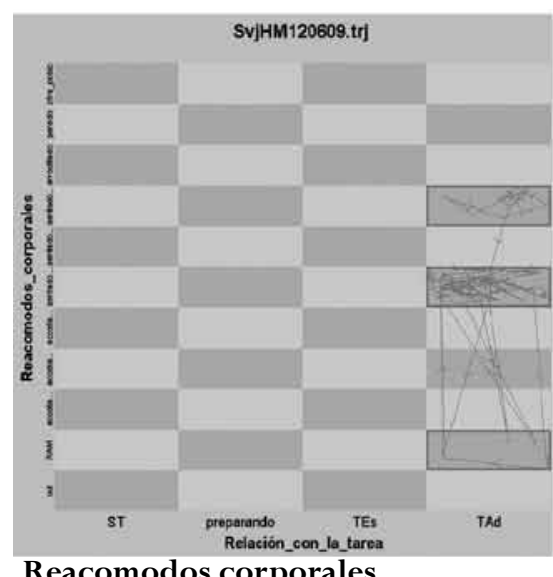

Reacomodos corporales

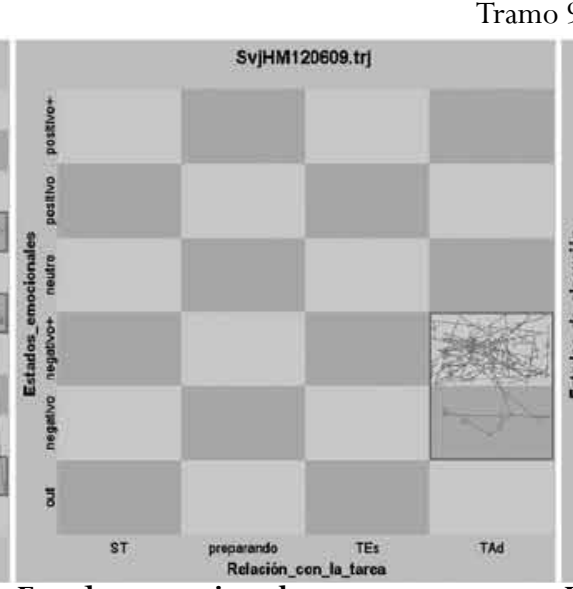

Estados emocionales

Tramo 9880-10470 (60 unidades de 10 segundos)

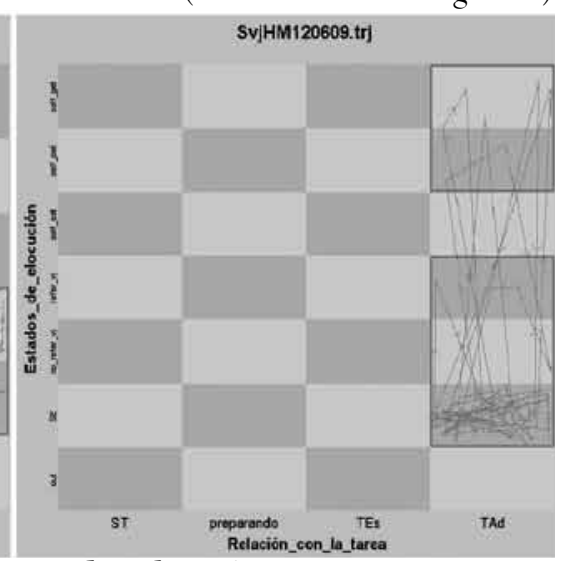

Estados Elocutivos

\section{Tramos de Videojuegos de Realización y Potenciación TE/TAD}

Se esperaría una muy alta inestabilidad de los tres vectores, explicable sobre todo por la fuerza de las restricciones temporales (TE) y la dificultad para encarar la tarea (TAD). Las restricciones de tiempo acentúan tanto la inestabilidad emocional como el uso de procedimientos de regulación y control del videojuego mediante movimientos RAM y fuerte actividad elocutiva self. Se presentaron 202 unidades de 10 segundos con características TAD y TE para videojuegos de realización y potenciación, diseminadas en seis tramos, con rangos de duración entre 7 y 56 unidades. En un $86,6 \%$ el comportamiento corporal, emocional y elocutivo se ajustó a lo esperado; en 9,9\%, parcialmente; y en un 3,4\% no se ajustó a lo esperado. A diferencia de los tramos de videojuegos de realización y potenciación con TA y TAD, en estos no sólo la inestabilidad fue significativa en los estados emocionales y elocutivos, sino también en los corporales, con importante presencia de movimientos RAM. Presentamos a continuación tres tramos que ilustran ajustes completos, parciales y completo desajustes respecto a los comportamientos esperados.

\section{Gráfico 10.Tramo con comportamientos ajus- tados al modelo.}

Se aprecia estabilidad corporal, con dos posiciones corporales estables y algunos pasajes RAM. Hay significativa inestabilidad emocional y elocutiva.

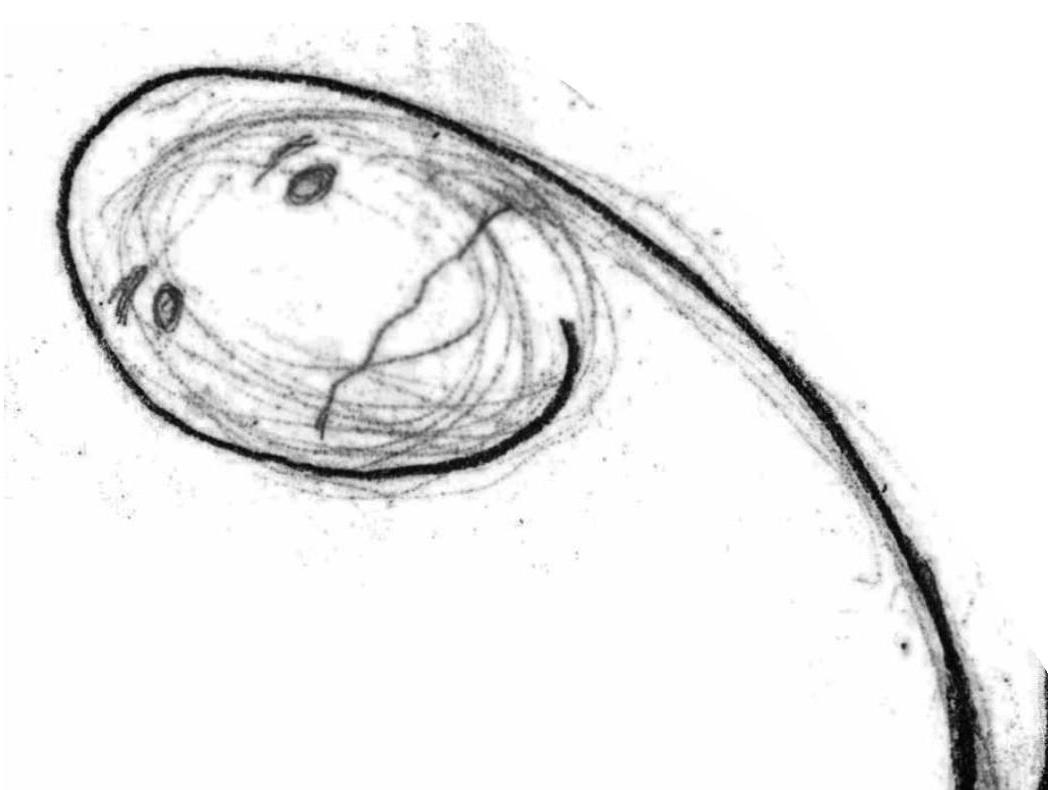


Tramo 5950-6360 (42 unidades de 10 segundos)

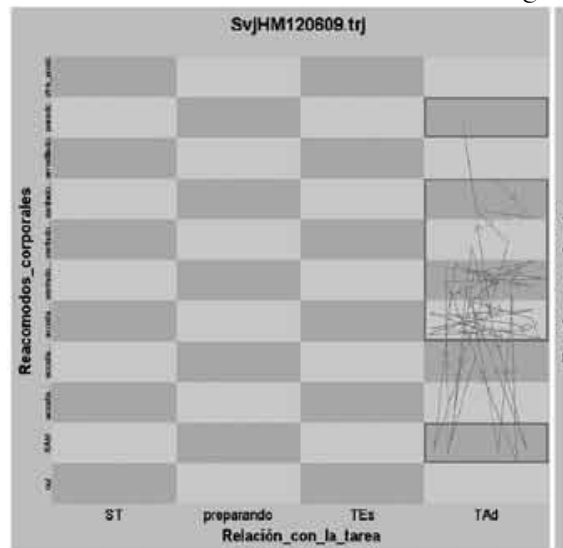

Reacomodos corporales

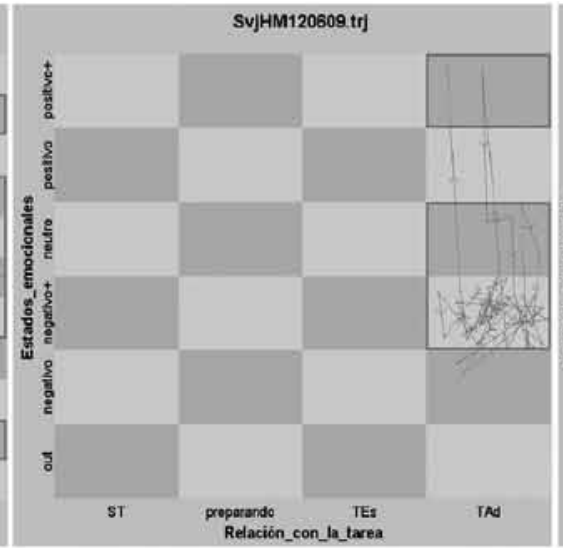

Estados emocionales

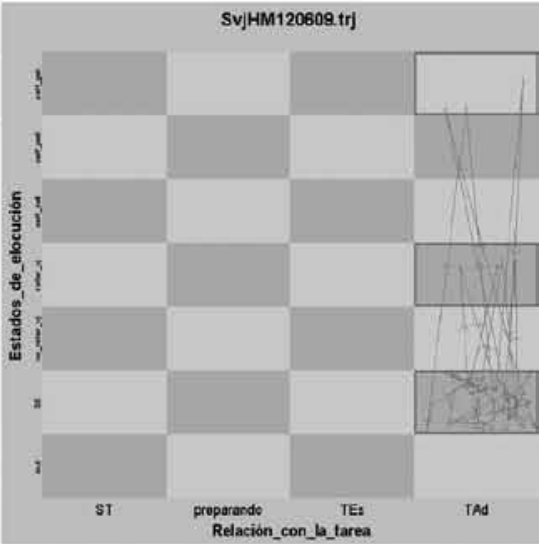

Estados Elocutivos

\section{Gráfico11.Tramo con comportamientos} ajustados al modelo.

Es una de las secuencias de videojuego continuo (González \&

Obando, 2010) más largas del estudio. Se aprecia fuerte inestabilidad corporal y emocional, con intensa inestabilidad elocutiva.

Tramo 8930-9120 (20 unidades de 10 segundos)

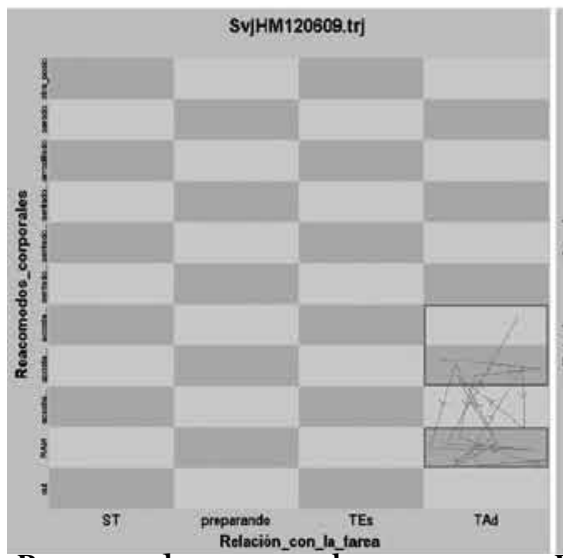

Reacomodos corporales

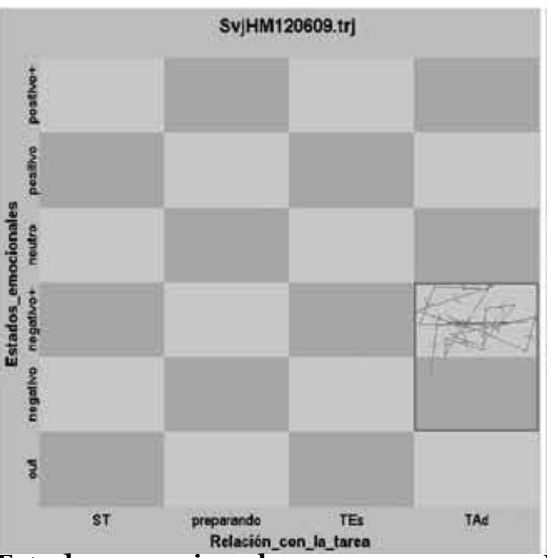

Estados emocionales

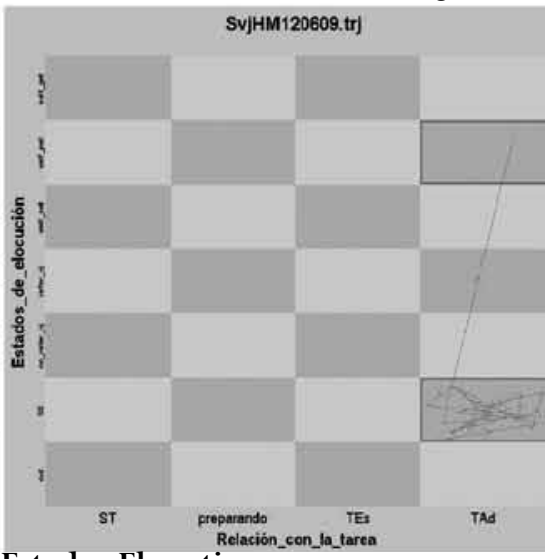

Estados Elocutivos

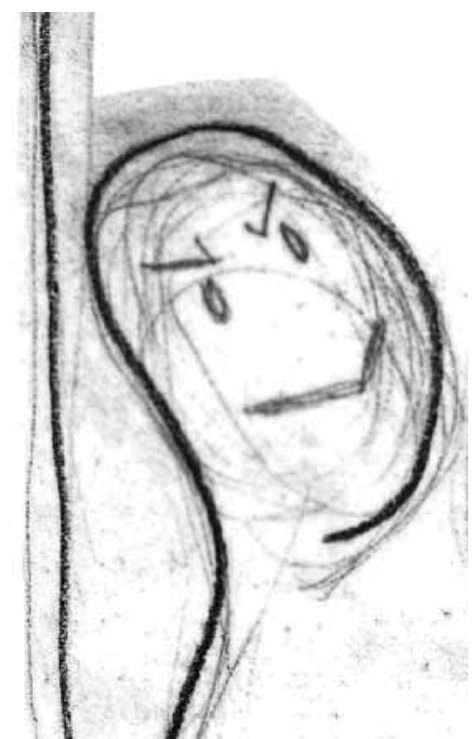

Gráfico 12. Tramo con comportamientos parcialmente ajustados al modelo.

Con fuerte inestabilidad corporal, con importantes eventos RAM, e importante inestabilidad emocional, este tramo presenta una significativa estabilidad elocutiva. Quizás debido a la notable inestabilidad corporal se inhibió el recurso compensatorio de la actividad. 


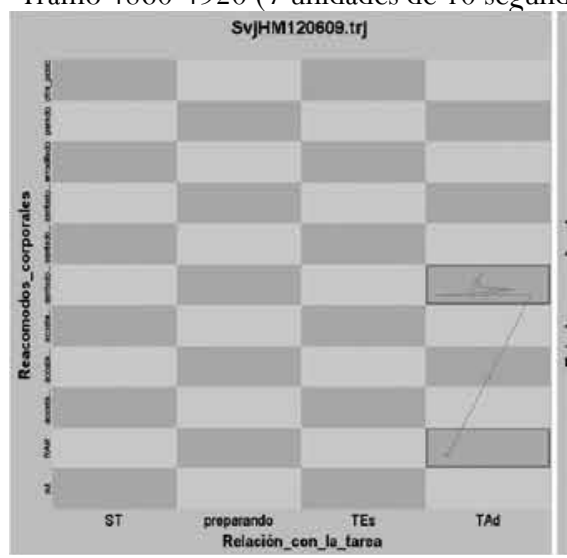

Reacomodos corporales

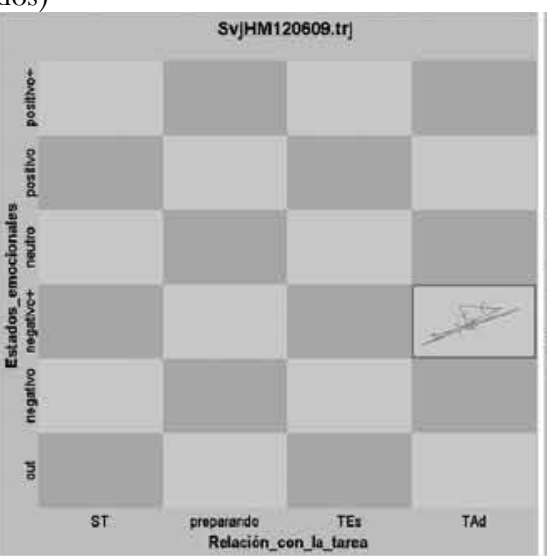

Estados emocionales

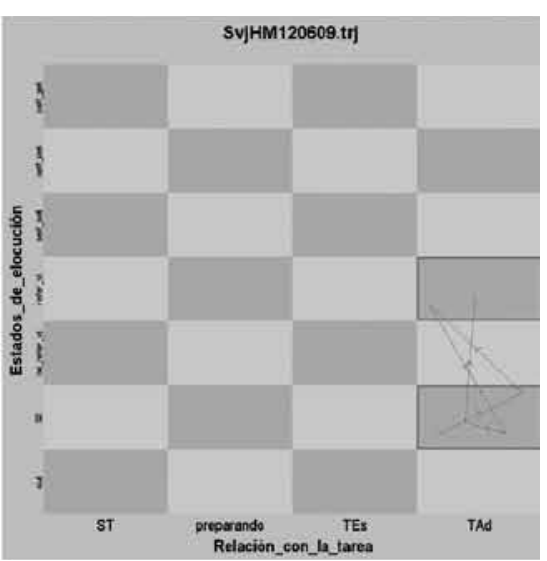

Estados Elocutivos

Gráfico 13. Tramo con comportamientos no ajustados al modelo.

Hay importante estabilidad corporal, significativa excitación emocional y moderada actividad elocutiva. No se ajusta

a la intensa inestabilidad esperada, de acuerdo

con la hipótesis planteada.

\section{Tramos deVideojuegos de Actualización/TAD}

Debido a la complejidad de los videojuegos y la relación TAD, es esperable una importante dinámica inestable, moderada ocasionalmente por el tipo de tiempo de resolución de la tarea (Tiempos Amplios). Sin embargo, es de suponer que este tipo de tramos deberían considerar la mayor inestabilidad del sistema, apenas superable por un hipotético videojuego de virtualización, con relacionesTAD y condiciones TE para realizar la tarea. En el estudio de la SVJ se presentaron 38 unidades de 10 segundos con este tipo de dinámica. Las 38 unidades de Videojuego de Actualización/ TAD se desarrollaron en tramos de 14, 6 y 8 unidades. En los tres tramos el comportamiento del sistema se ajusta perfectamente a los patrones esperados: alta inestabilidad en las posiciones corporales, con fuerte presencia de movimientos RAM; alta inestabilidad en los estados emocionales, esto es, estados no neutros; y significativa actividad elocutiva, con presencia de eventos elocutivos self-GET. Es decir en el 100\% de los tramos se presentan alta inestabilidad. A continuación una ilustración de uno de los tres tramos en que se aprecia importante inestabilidad en los tres comportamientos.

Tramo 2230-2360 (14 unidades de 10 segundos)

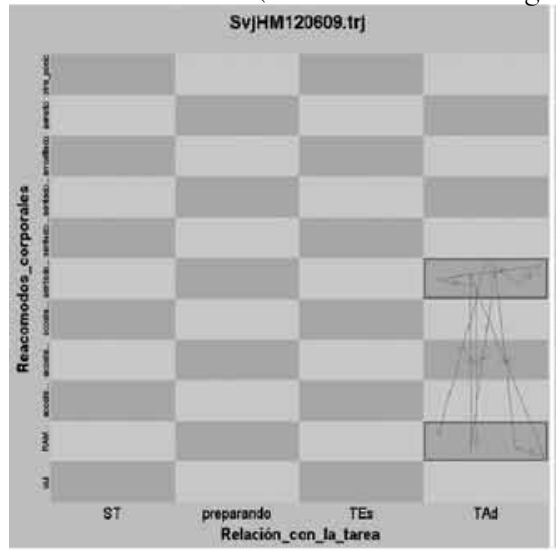

Reacomodos corporales

Gráfico 14. Tramo con comportamientos ajustados al modelo.

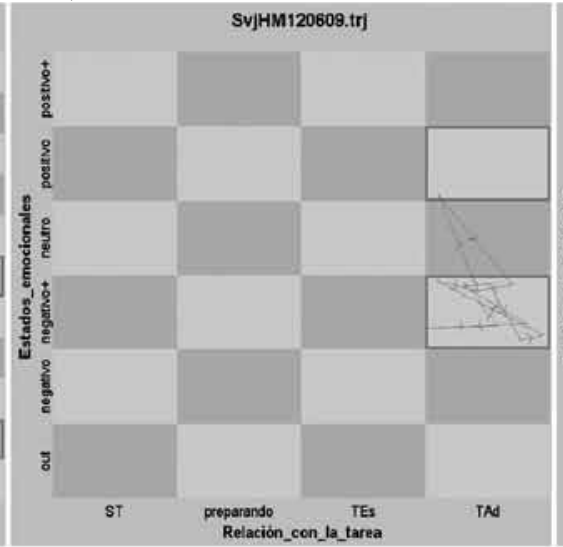

Estados emocionales

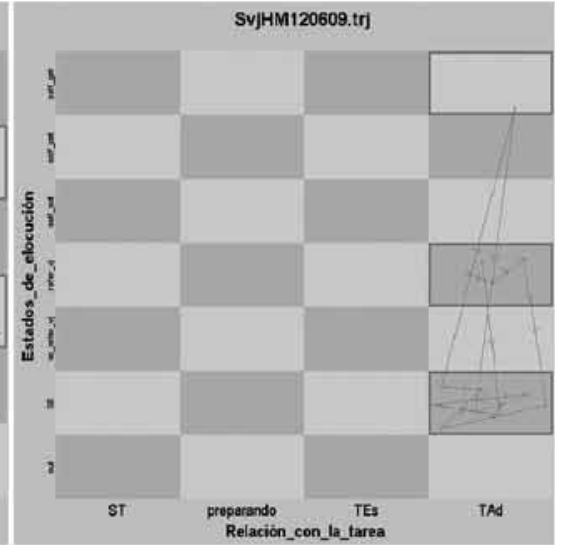

Estados Elocutivos
Es particularmente significativa la presencia de dinámica RAM y el estado emocional negativo + en este tramo. Un poco menos intensa resulta la dinámica elocutiva, con presencia de eventos elocutivos referidos al videojuego y un evento self-GET. El tramo se ajusta a la hipótesis planteada. 


\section{Conclusiones}

En resumen, la hipótesis de la estabilidad/inestabilidad de las dinámicas elocutivas, corporales y emocionales, según se trate de videojuegos de realización TA/TE, de potenciación TA/TE, de actualización y de virtualización, y según el videojugador cuente con mayor o menor dominio sobre el videojuego (TES o TAD) parece verificarse -para esta SVJ- en todos los casos, con excepción de los tramos correspondientes a videojuegos de realización y potenciación TA/TES, en los que se encontró mayor inestabilidad de la esperada en la mitad de los casos. En el futuro, el seguimiento detallado de todas las SVJ del niño HMG, el examen de las SVJ en el niño NOG y el estudio de nuevas SVJ en otros niños videojugadores, nos va a permitir introducir ajustes y refinar el modelo apenas esbozado en este artículo. La emergencia de soluciones inesperadas tras los momentos críticos o de alta inestabilidad, el modo como el niño videojugador regula la abrumadora presencia de eventos periféricos que amenazan con sacarlo de la SVJ, la manera como transforma ciertos descubrimientos operacionales y ciertas formas de manipular los controles de videojuego para mejorar su dominio sobre cada videojuego, se irán revelando en los futuros estudios de estas SVJ registradas en video y cuyos data han sido tratados usando Grideware y su interfase gráfica generada (State Space Grid), un software que ofrece no sólo una importante representación visual de los fenómenos, sino prometedores modos de hacer seguimiento y comparaciones de trayectorias y dinámicas en el tiempo.

La práctica de videojugar parece revelar dimensiones y rasgos cuyos alcances estamos en mora de comprender. La presencia de una significativa actividad elocutiva, los movimientos RAM y los continuos reacomodos corporales, los cambiantes estados emocionales no deberían considerarse fenómenos periféricos y externos a los procesos de resolución y desarrollo de los videojuegos. El videojugador que agita repetidamente las manos y la cabeza o balancea nerviosamente los pies y los brazos está resolviendo a través de estos gestos el videojuego. El examen de algunos de los aspectos más significativos de una Situación de Videojuego nos permite apreciar cómo convergen estos fenómenos y hasta qué punto parecen acentuarse cuando aumenta la dificultad de la tarea de videojuego. El videojugar silencioso y el videojugar elocutivo van tomando lugar a lo largo del desarrollo de la SVJ, pautando y estructurando la actividad más allá de las restricciones y prescripciones contenidas en la gramática y arquitectura del videojuego. En otras palabras, así como el libro que promete el autor, no es el libro que se procura el lector; el videojuego, los contenidos y secuencias que se prevén en el diseño lógico, no son los que el videojugador interpreta haciéndose a una comprensión que pasa por el cuerpo, la palabra y la emoción. La resolución dinámica de un videojuego contrasta con lo que podría esperarse de una resolución lógica y mentalista del mismo. La dificultad, falta de pericia, la complejidad de la tarea de videojuego, aunadas a las restricciones temporales para su resolución procuran una suerte de inestabilidad generalizada del sistema SVJ. En el seno de esta inestabilidad parecieran emerger soluciones inesperadas, descubrimientos y maneras de resolver el videojuego, que posteriormente el videojugador estabilizada, aprende y automatiza. Fue en uno de estos momentos de alta inestabilidad que HMG descubrió las posibilidades que ofrece pausar rápida y consecutivamente una secuencia de videojuego de realización TE para encontrar modos de operarla y resolverla más eficientemente. El estudio y análisis de nuevas SVJ con niños diversos y en circunstancias particulares y cambiantes nos van a ir revelando algo que podría resumirse y sintetizarse en una sola palabra: también se piensa con los pies.

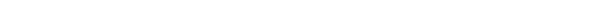




\section{Notas:}

${ }^{1}$ Y tutora del proyecto de investigación "Niños que videojuegan: videojuegos que estructuran tiempos”, del estudiante Julián González, del cual deriva este artículo. Este artículo hace parte de la producción intelectual del Grupo de Investigación de Desarrollo Psicológico en Contextos, del Centro de Investigaciones en Psicología, Cognición y Cultura de la Universidad del Valle. Olga Lucía Obando:olgaob@yahoo.de. Julián González: jugonza@univalle.edu.co.

${ }^{2}$ No se han presentado hasta ahora elocuciones no clasificables en nuestro estudio.

${ }^{3}$ La codificación de las Situaciones de Videojuego considera las iniciales del nombre del videojugador, seguidas de la fecha en que se desarrolló la situación, indicando día, mes y año.

${ }^{4}$ TA y TE son términos para diferenciar entre aquellos videojuego en que hay restricciones de tiempo para resolver la tarea específica del videojuego (TE o Tiempo Estrecho) y aquellos en que no hay restricciones de tiempo (TA o Tiempo Amplio) para la resolución de la tarea.

${ }^{5}$ Sólo en la unidad 710, el niño comienza el proceso de instalación del videojuego, y en la unidad 10720 suspende la SVJ para irse a almorzar.

${ }^{6}$ Están incluyen 45 unidades en las que se presentan eventos de selección de caracteres del videojuego y entrenamiento. Ambos tipos de actividad han sido clasificados como procesos de realización de Tiempos Amplios.

\section{Referencias}

Draghi-Lorenz, R.; Reddy, V. \& Costall, A. (2001) Rethinking the Development of "Nonbasic" Emotions: A Critical Review of Existing Theories. Developmental Review 21, pp 263-304. Obtenido de http: / /www.idealibrary.com

González, J. \& Obando, O. (2008a). Clasificar los videojuegos como tarea dinámica. En Revista Nexus No.4. Escuela de Comunicación Social, Universidad del Valle. Cali.

(2008b). Mapear los eventos temporales en las situaciones de videojuegos. En Revista Nexus No 4. Escuela de Comunicación Social, Universidad del Valle. Cali.

González \& Obando (2010) Pautando los ritmos del videojugar: juego elocutivo y silencioso, juego continuo y fractura. Revista Nexus, No. 8 Escuela de Comunicación Social, Universidad del Valle.

Harris, P.; de Rosnay, M. \& Pons, F. (2005) Language and Children's Understanding of Mental Status. Obtenido de www.erin.utoronto. $\mathrm{ca} / \sim_{\text {w3psygs / 05PSY210F/Harris2005.pdf. }}$

Hollenstein, T. (2007) State space grids: Analyzing dynamics across development. En International Journal of Behavioral Development 2007, 31 (4), 384-396. Obtenido de http: / /www.statespacesgrids.org.

Lamey, A., Hollenstein, T., Lewis, M.D., \& Granic, I (2004). GridWare (Version 1.1). Computer software. Obtenido de http://statespacegrids.org

Lévy, Pierre (1999). ¿Qué es lo virtual? Barcelona: Paidos.

Lewis, M. D., Lamey, A. V., \& Douglas, L. (1999). A new dynamic systems method for the analysis of early socioemotional development. Developmental Science, 2, pp. 458-476.

Thelen, E. (1986) Treadmill-Elicited Stepping in Seven-Month-Old Infants. En Child Development, Vol. 57, No. 6, (Dec., 1986), pp. 1498-1506

Thelen, E.; Ulrich, B.D. \& Wolff, P.H. (1991) Hidden Skills: A Dynamic Systems Analysis of Treadmill Stepping during the First Year. Monographs of the Society for Research in Child Development, Vol. 56, No. 1, pp. i+iii+v-vi+1-103

Thelen, E. et al., (1993) The Transition to Reaching: Mapping Intention and Intrinsic Dynamics. Child Development, Vol. 64, No. 4, (Aug., 1993), pp.1058-1098.

Varela, F. (1999) Present-Time Consciousness. En Journal of Consciousness Studies No. 6, No. 2-3, pp. 111-140. 